\title{
On the competition between the stress-induced formation of martensite and dislocation plasticity during crack propagation in pseudoelastic NiTi shape memory alloys
} DOI:

10.1557/jmr.2017.267

\section{Document Version \\ Accepted author manuscript}

Link to publication record in Manchester Research Explorer

Citation for published version (APA):

Ungar, H. T., Frenzel, J., Gollerthan, S., Ribárik, G., Balogh, L., \& Eggeler, G. (2017). On the competition between the stress-induced formation of martensite and dislocation plasticity during crack propagation in pseudoelastic NiTi shape memory alloys. Journal of Materials Research, 1-10. https://doi.org/10.1557/jmr.2017.267

\section{Published in:}

Journal of Materials Research

\section{Citing this paper}

Please note that where the full-text provided on Manchester Research Explorer is the Author Accepted Manuscript or Proof version this may differ from the final Published version. If citing, it is advised that you check and use the publisher's definitive version.

\section{General rights}

Copyright and moral rights for the publications made accessible in the Research Explorer are retained by the authors and/or other copyright owners and it is a condition of accessing publications that users recognise and abide by the legal requirements associated with these rights.

\section{Takedown policy}

If you believe that this document breaches copyright please refer to the University of Manchester's Takedown Procedures [http://man.ac.uk/04Y6Bo] or contact uml.scholarlycommunications@manchester.ac.uk providing relevant details, so we can investigate your claim.

\section{OPEN ACCESS}




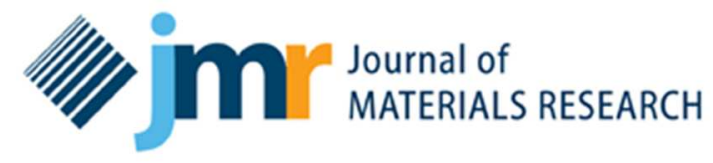

\section{On the competition between the stress induced formation of martensite and dislocation plasticity during crack propagation in pseudoelastic NiTi shape memory alloys}

\begin{tabular}{|r|l|}
\hline Journal: & Journal of Materials Research \\
\hline Manuscript ID & JMR-2017-0455.R1 \\
\hline Manuscript Type: & $\begin{array}{l}\text { Focus Issue: Mechanical Properties and Microstructure of Advanced Metallic } \\
\text { Alloys-in Honor of Prof. Hael Mughrabi }\end{array}$ \\
\hline Date Submitted by the Author: & n/a \\
\hline Complete List of Authors: & $\begin{array}{l}\text { Ungar, Tamas; Eotvos University Budapest, Hungary, Department of } \\
\text { Materials Physics; University of Manchester, School of Materials } \\
\text { Frenzel, Jan; Faculty of Mechanical Engineering, Ruhr-University Bochum, } \\
\text { Institute for Materials } \\
\text { Gollerthan, Susanne; Faculty of Mechanical Engineering, Ruhr-University } \\
\text { Bochum, Institute for Materials } \\
\text { Rbárik, Gábor; Eotvos Lorand Tudomanyegyetem, Department of Materials } \\
\text { Physics } \\
\text { Balogh, Levente; Queen's University , Department of Mechanical and } \\
\text { Materials Engineering } \\
\text { Eggeler, Gunther; Ruhr-Universität Bochum, Fakultät Maschinenbau, } \\
\text { Institut für Werkstoffe Lehrstuhl Werkstoffwissenschaft }\end{array}$ \\
\hline Key Words: & \begin{tabular}{l} 
fracture, x-ray diffraction (XRD), alloy \\
\hline
\end{tabular} \\
\hline
\end{tabular}




\title{
On the competition between the stress induced formation of martensite and dislocation plasticity during crack propagation in pseudoelastic NiTi shape memory alloys
}

\author{
T. Ungár ${ }^{\mathrm{a}, \mathrm{d}}$, J. Frenzel ${ }^{\mathrm{b}}$, S. Gollerthan ${ }^{\mathrm{b}}$, G. Ribárik ${ }^{\mathrm{a}}$, L. Balogh${ }^{\mathrm{a}, \mathrm{c}}$, G. Eggeler ${ }^{\mathrm{b}}$, \\ ${ }^{a}$ Department of Materials Physics, Eötvös University Budapest, P.O. Box 32, H-1518 Budapest, \\ Hungary \\ ${ }^{\mathrm{b}}$ Institut für Werkstoffe, Ruhr-Universität Bochum, 44801 Bochum, Germany \\ ${ }^{c}$ Department of Mechanical and Materials Engineering, Queen's University, Kingston, Ontario, \\ Canada, \\ ${ }^{\mathrm{d}}$ School of Materials, The University of Manchester, Manchester, M13 9PL, UK
}

Dedicated to the $80^{\text {th }}$ Birthday of Professor Haël Mughrabi

\begin{abstract}
The present work addresses the competition between dislocation plasticity and stress induced martensitic transformations in crack affected regions of a pseudoelastic NiTi miniature CT specimen. For this purpose X-ray line profile analysis was performed after fracture to identify dislocation densities and remnant martensite volume fractions in regions along the crack path. Special emphasis was placed on characterizing sub fracture surface zones to obtain depth profiles. The stress affected zone in front of the crack tip is interpreted in terms of a true plastic zone associated with dislocation plasticity and a pseudoelastic zone where stress induced martensite can form. On unloading, most of the stress induced martensite transforms back to austenite but a fraction of it is stabilized by dislocations in both, the irreversible martensite and the surrounding austenite phase. The largest volume fraction of the irreversible or remnant martensite along with the highest density of dislocations in this phase was found close to the
\end{abstract}


primary crack-tip. With increasing distance from the primary crack tip both, the dislocation density and the volume fraction of irreversible martensite decrease to lower values.

Keywords: Shape memory alloys (SMAs), fracture mechanics, X-ray line profile analysis, dislocation plasticity, remnant martensite

corresponding author: Tamás Ungár,ungar@ludens.elte.hu 


\section{Introduction}

NiTi shape memory alloys (SMAs) are functional materials which undergo martensitic transformations $[1,2]$. Depending on the Ni-content, they can show the one way effect (1WE) and pseudo-elasticity (PE) [1-4]. SMAs are used in engineering and medical technology [5,6], with good static [7-9] and cyclic toughness [10-13]. Fracture mechanisms in PE SMAs are of recent interest [14-24]. Gollerthan et al. [15-17] used compact tension (CT) specimens to study the behavior of cracks in NiTi SMAs. Their experiments focused on the formation of the pseudoelastic zone around the crack tip and showed that cracks always propagate into microstructures consisting of favorably oriented martensite variants. Synchrotron experiments revealed that stress induced martensite forms in a region extending almost $2 \mathrm{~mm}$ at the front of the crack tip [16]. Thermography experiments showed the heat effects associated with the forward and reverse martensitic transformations [16,17]. The synchrotron experiments revealed the butterfly shaped elastic strain distribution around the crack-tip [19]. Finite element calculations of the PE zone around the crack-tip support the experimental results, e.g. [14, 21-26]. Forward transformation during loading improves fracture toughness and reduces the size of the stress affected zone in front of the crack-tip [14,21-26]. Reverse transformation during unloading can counteract this toughness enhancement $[25,26]$.

Figure 1. shows the schematic sequence of the main steps in testing fracture [15]. Above the critical stress intensity, $\mathrm{K}_{\mathrm{I}}{ }^{*}$, the crack starts growing. Figure 1a shows the dimensions of our CT specimen. For $0<\mathrm{K}_{\mathrm{I}}<\mathrm{K}_{\mathrm{I}} *$ only the grips are strained. The crack propagates when $\mathrm{K}_{\mathrm{I}}>\mathrm{K}_{\mathrm{I}}{ }^{*}$. Figure 1c. shows the crack before rupture, and $1 \mathrm{~d}$. shows the ruptured state. To understand crack propagation in SMAs we have to understand stress induced martensitic transformation along with dislocation plasticity in the stress affected zone ahead of the crack-tip.

In the present work we investigate the ruptured CT-specimen shown in Figure 1d. using X-ray line profile analysis. We determine the extension of the true plastic zone around the primary crack-tip by determining the dislocation density in the plastically deformed material and the volume fraction of irreversible martensite as a function of the distance from the pre-cracked primary crack-tip and the depth below the fracture surface. We show that adjacent to the fracture 
surface, where stress-induced martensite does not transform back to austenite, (i) the irreversible martensite is stabilized by enhanced dislocation densities in the austenite and martensite components and (ii) that this zone is about one order of magnitude smaller than the pseudoelastic zone determined by in-situ synchrotron experiments on similar specimens $[14,16]$.

\section{Experimental}

\subsection{Sample}

The present work was performed on a pseudoelastic NiTi material, described in more detail in references $[15,16]$. We used CT specimens of 50.7 at.\% Ni showing pseudoelastic behavior at room temperature. A sharp crack-tip of about $1.08 \mathrm{~mm}$ length was produced by fatigue precracking. The crack propagation tests and conventional tensile tests were carried out in a tensile test machine of type Z100 equipped with a climate chamber to ensure a constant temperature of $20^{\circ} \mathrm{C}$. Displacements were determined using an extensometer of type MTS 632.13F-23. A typical stress-strain curve of our material is shown in Figure 2a. The stress-strain plateaus in Figure 2a correspond to the formation of stress induced martensite during loading and to the reverse transformation during unloading. The displacement controlled load-displacement, P- $\Delta$, curve of our specimen is shown in Figure 2b. The figure shows a short stable crack-growth region, denoted as II. This is followed by the fast unstable crack-growth region III, where the load drops abruptly. In the last region, IV, the force is mainly compressive. Here the stress state is complicated which we do not interpret in the present work.

The in-situ synchrotron experiments in $[15,16]$ were done at $2860 \mathrm{~N}$, below the critical load, where $\mathrm{K}_{\mathrm{I}}<\mathrm{K}_{\mathrm{I}}{ }^{*}$. The volume fractions of the pseudoelastic transformed martensite are shown in Figure 7a. in reference [16]. A section of this figure is shown in Figure 3a. The primary crack-tip is indicated by the first vertical arrow on the left. The post-mortem microbeam laboratory X-ray diffraction experiments were carried out at three positions along the fracture surface indicated by the three vertical arrows in Figure $3 \mathrm{a}$ and repeated below the fracture surface shown schematically in Figure 3b. 


\subsection{X-ray diffraction}

The X-ray diffraction experiments were carried out using a double-crystal diffractometer with a symmetrically cut plane Ge primary monochromator using the (220) reflection [27]. The Nonius FR 591 rotating copper anode was operated at $4 \mathrm{~kW}$ with a fine line focus of $0.3 \times 3 \mathrm{~mm}^{2}$ true focal size. A narrow slit in front of the monochromator was adjusted to eliminate $\mathrm{CuK \alpha} \alpha_{2}$ radiation. After the monochromator a second slit of $0.2 \times 2 \mathrm{~mm}^{2}$, close to the specimen, blocks parasitic scattering from the monochromator and reduces beam divergence normal to the incidence plane. The distance between the X-ray source and the specimen was $460 \mathrm{~mm}$. This setup provides a monochromatic and almost parallel beam with a divergence less than about $0.025^{\circ}$ in the plane of incidence. The footprint of the beam on the specimen was about $0.2 \times 2$ $\mathrm{mm}^{2}$. The diffracted beam was recorded using two curved image plates (IP) with a linear spatial resolution of $50 \mu \mathrm{m}$. The IPs were positioned at a distance of $200 \mathrm{~mm}$ from the stationary specimen, covering the angular range from $2 \theta=30$ to $140^{\circ}$. Since, in the present case, the narrowest diffraction peaks in all measured diffraction patterns were at least one order of magnitude broader than the instrumental breadth of $0.057^{\circ}$, there was no need for instrumental corrections. The position of the X-ray beam on the specimen surface was determined by using a low depth-resolution microscope coupled to a TV-screen.

At first the virgin fracture surface was measured. After finishing the three diffraction patterns at the three positions, the specimen was successively chemical etched to measure the diffraction patterns at different depths from the fracture surface as shown schematically in Figure $3 \mathrm{~b}$. The blue region is the fatigue pre-cracking. The three red lines indicate the distance of measurement positions from the primary crack-tip. Depth profiling was done by stepwise removing layers of defined thicknesses by chemical etching. During etching the side and bottom faces of the specimen were covered by etchant resistant synthetic lack. The thickness of the removed layers was controlled by weighing the sample with an accuracy of $10 \mu \mathrm{g}$. The aim of thickness removal was $15 \mu \mathrm{m}$ in 4 steps. Figure 4 shows the measured depths after layer removal. The actual measured values come quite close to the targeted $15 \mu \mathrm{m}$ steps. After the 4 layers were removed, a thicker layer of about $200 \mu \mathrm{m}$ was removed to reach a depth, significantly below the rupture surface. 


\section{Evaluation of the X-ray diffraction patterns}

The diffraction patterns are evaluated by using the convolutional multiple whole profile (CMWP) procedure [28-30]. The method is based on physically well-established profile functions theoretically calculated for different specific lattice defects, in particular for (i) coherently scattering domain size, (ii) dislocations and (iii) various planar defects. The size profile function is given by the median, $\mathrm{m}$, and the variance, $\sigma$, for the coherently scattering domain size. The strain profile function is given by the density, $\rho$, the contrast factors, $C$, and the arrangement parameter, M, of dislocations. The profile function of planar defects is given as the sum of a symmetric and antisymmetric Lorentz functions vs. the density of the faults [30]. The calculated diffraction pattern is produced by convoluting the defect related, theoretically calculated profile functions. The calculated and measured diffraction patterns are matched together by adjusting the physical parameters listed above. Instrumental effects are also convoluted in CMWP with the physical profiles. The background is determined either manually or by a background fitting. The calculated and measured patterns are matched by the combined Marquard-Levenberg and MonteCarlo procedures in order to obtain the global minimum for the difference between the measured and calculated patterns [31]. The CMWP procedure has the option to evaluate more than one phase in parallel. This is used to determine the microstructure in the austenite and the irreversible martensite phases separately and simultaneously.

\subsection{Evaluation of the dislocation density}

The Fourier transform of the strain profile can be written as [30]:

$A_{h k l}^{D}(\mathrm{~L}) \cong \exp \left[-2 \pi^{2} g^{2} L^{2}\left\langle\varepsilon_{g, L}^{2}\right\rangle\right]$

where $g$ is the absolute value of the diffraction vector, $L$ is the Fourier variable and $\left\langle\varepsilon_{g, L}^{2}\right\rangle$ is the mean square strain. For dislocated crystals the mean square strain was elaborated by Krivoglaz [32], Wilkens [33] and Groma et al. [34]: 
$\left\langle\varepsilon_{g, L}{ }^{2}\right\rangle \cong \frac{\rho C b^{2}}{4 \pi} f(\eta)$

$\rho$ and $\mathrm{b}$ are the density and the Burgers vector of dislocations, $C$ is the dislocation contrast factor and $f(\eta)$ is the strain function. The function $f(\eta)$ describes the $L$ dependence of the mean-squarestrain with $\eta=L / R_{\mathrm{e}}$, where $R_{\mathrm{e}}$ is the effective outer cut-off radius of dislocations. The physical meaning of $R_{\mathrm{e}}$ here is the same as in the elastic stored energy of dislocations [35]. $R_{\mathrm{e}}$ is rationalized as the dipole character of dislocations arrangements by introducing the arrangement parameter $M=R_{\mathrm{e}} \sqrt{\rho}$ [33]. If $M$ is smaller or larger than unity, the dipole character of dislocations is stronger or weaker. $M$ correlates with the profile shape. For smaller or larger $M$ values the tails of diffraction peaks become longer or shorter, respectively [29,30,33].

\subsection{Evaluation of the volume fraction of the remnant martensite}

The volume fraction of the irreversible martensite was determined as the ratio of the sum of peak areas of the $\overline{1} 01,101,1 \overline{1} 1,020$ and 012 reflections of the $\mathrm{B} 19^{\prime}$ phase relative to the peak area of the 110 peak of the B2 phase. The B19' volume fraction at the fracture surface at the crack tip was adjusted to the value corresponding to the dark-brown region in Figure 3 a as $f \cong 35( \pm 10) \%$ (Figure 3a was kindly provided Gollerthan et al., see Figure 7a in reference [16]).

\section{Results}

Representative measured and CMWP calculated diffraction patterns are shown in Figure 4. The diffraction pattern measured on the fracture surface at the primary crack-tip is shown in Figure 4a. The largest intensity around $2 \theta=42.7^{\circ}$ corresponds to the 110 reflection of the $\mathrm{B} 2$ austenite

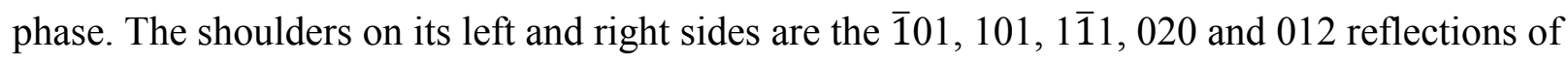
the B19' irreversible martensite phase. The constituent CMWP calculated profiles of the B19' phase (solid black lines) along with the CMWP calculated 110 profile of the B2 phase (dashed blue line) are shown in Figure 4b. Measured (open circles) and CMWP calculated (red lines) diffraction patterns corresponding to the fracture surface at $4 \mathrm{~mm}$ from the primary crack-tip and 
$59.6 \mu \mathrm{m}$ below the fracture surface, below the primary crack-tip, are shown in Figure 4c and 4d, respectively.

The depth profile of the dislocation density, $\rho$, in the B19' remnant martensite phase is shown in Figure 5a. It is $\rho \cong 6.5 \times 10^{15}\left( \pm 1 \times 10^{15}\right) \mathrm{m}^{-2}$ at the primary crack-tip and stays large along the fracture surface between 3 and $4 \times 10^{15}\left( \pm 0.5 \times 10^{15}\right) \mathrm{m}^{-2}$. Below the fracture surface it decreases to about $1 \times 10^{15}\left( \pm 0.5 \times 10^{15}\right) \mathrm{m}^{-2}$ at a depth of $30 \mu \mathrm{m}$. Below this depth it is in the range between about 1 and $3 \times 10^{15}\left( \pm 2 \times 10^{15}\right) \mathrm{m}^{-2}$. The large experimental error in this depth range is due to the very low martensite fractions decreasing to less than $5 \%$, see Figure $6 a$. The depth profile of $\rho$ in the B2 austenite phase is shown in Figure $5 \mathrm{~b}$ and $5 \mathrm{c}$ in linear and logarithmic scales, respectively. Figure $5 \mathrm{~b}$ shows that $\rho$ in B2 is very large at the fracture surface and decreases rapidly with depth. Also, $\rho$ is considerably smaller at the primary crack-tip along the fracture surface than at the far end from it. The logarithmic scale figure (5c) reveals that (i) at the primary crack-tip $\rho \cong 3 \times 10^{15}\left( \pm 1 \times 10^{15}\right) \mathrm{m}^{-2}$ and it increases with depth below the primary crack-tip to about $\rho \cong 10 \times 10^{15}\left( \pm 2 \times 10^{15}\right) \mathrm{m}^{-2}$. Below $\sim 50 \mu \mathrm{m} \rho$ decreases to about $\rho \cong 1 \times 10^{15}\left( \pm 0.5 \times 10^{15}\right) \mathrm{m}^{-2}$. (ii) At the far-end from the primary crack-tip on the fracture surface $\rho$ is $\rho \cong 64 \times 10^{15}\left( \pm 5 \times 10^{15}\right) \mathrm{m}^{-2}$ and it decreases gradually to about $\rho \cong 4 \times 10^{15}\left( \pm 1 \times 10^{15}\right) \mathrm{m}^{-2}$ at a depth of $60 \mu \mathrm{m}$. At the depths of about $200 \mu \mathrm{m}$ below the fracture surface the dislocation density was obtained to be $\rho \cong 0.2 \times 10^{15}\left( \pm 0.05 \times 10^{15}\right) \mathrm{m}^{-2}$, which is equal to the dislocation density of the undeformed alloy.

The depth profile of the relative change of the volume fraction, $f$, of the remnant martensite is shown in Figure 6a. The figure shows that (i) $f$ decreases almost to zero at a depth of about $60 \mu \mathrm{m}$ from the fracture surface below the primary crack-tip, (ii) at the far-end of the fracture surface it is about $f \cong 0.15( \pm 0.03)$ and does not decrease below about $f \cong 0.08( \pm 0.02)$ even at a depth of 60 $\mu \mathrm{m}$ and (iii) halfway between the primary crack-tip and the far end of the fracture surface it is about $f \cong 0.15( \pm 0.03)$ but decreases relatively fast to a low level of about $f \cong 0.04( \pm 0.02)$ and stays constant down to $60 \mu \mathrm{m}$ below the fracture surface. $200 \mu \mathrm{m}$ deep below the fracture surface no remnant martensite was detected by the present X-ray diffraction method. 
The depth profile of $<x>_{\text {area }}$, in the remnant martensite is shown in Figure $6 \mathrm{~b}$. In plastically deformed bulk materials the X-ray determined $<\mathrm{X}\rangle_{\text {area }}$ values best correlate with the subgrain size, which is usually smaller than the grain size in the material $[39,40]$. Therefore, next we will call $<\mathrm{x}>_{\text {area }}$ the subgrain size. In B19' it is between 6 and $8 \mathrm{~nm}$ at the fracture surface. It reveals a maximum halfway between the primary crack-tip and far end of the specimen at a depth of $\sim 15$ $\mu \mathrm{m}$. At the depth of $30 \mu \mathrm{m}$ goes down to about $5 \mathrm{~nm}$. Below $30 \mu \mathrm{m}$ the subgrain size values become uncertain because of the low volume fraction of B19'. The depth profile of the subgrain size in B2 is shown in Figure 6c. It is of the order of $5( \pm 2) \mathrm{nm}$, at the primary crack-tip and gradually increases to a somewhat larger value of about $40( \pm 10) \mathrm{nm}$ with depth and distance from it.

\section{Discussion}

\subsection{Correlation between dislocation densities and the fraction of remnant martensite}

In-situ synchrotron X-ray diffraction experiments in $[16,19]$ have shown that martensitic transformation extends as deep as $\pm 2.5 \mathrm{~mm}$ from the fracture surface. The spatial distribution and the volume fraction of martensite transforming during loading is shown in Figure 3a (by courtesy from [16]). The present X-ray diffraction experiments were carried out on the fractured specimen and therefore all detected martensite is obviously remnant martensite. The fraction of irreversible martensite, shown in Figure 6a, drops fast to low levels smaller than about $10( \pm 4) \%$ at depths lower than $30 \mu \mathrm{m}$ from the fracture surface. A comparison of Figures $6 \mathrm{a}$ and $5 \mathrm{a}$ indicates that there is a strong correlation between the fractions and the dislocation densities in the remnant martensite phase. The high dislocation density in the B19' phase suppresses the reverse transformation to austenite, which is expected while the CT specimen is unloaded during crack propagation and the final fracture. At the same time, the dislocation density in the austenite phase seems to be in anti-correlation with the remnant martensite fraction, as indicated by comparing Figures $5 \mathrm{~b}$ and $6 \mathrm{a}$. 


\subsection{The effect of crack-growth rate on the fraction of remnant martensite and the dislocation densities in austenite and martensite}

Crack propagation and the formation of irreversible martensite are interpreted in terms of the load-displacement, P- $\Delta$ behavior, shown in Figure $2 \mathrm{~b}$. According to the deformation rate we define four characteristic sections: (I) an almost linear section where the load increases up to its maximum at about $\Delta \cong 800 \mu \mathrm{m}$, (II) a plateau region with constant load where $\Delta$ is about $800<\Delta<920 \mu \mathrm{m}$, (III) a short decrease of the load where $\Delta$ is about $920<\Delta<950 \mu \mathrm{m}$, and (IV) above $\Delta \cong 950 \mu \mathrm{m}$, where the load drops abruptly and the specimen breaks. Loading was performed displacement controlled and therefore the lengths of the regions are proportional to the time intervals in which the microstructural processes under investigation take place, especially in the first three regions. In region I the grips of the CT specimen are strained elastically and the load on the primary crack-tip increases. In region II, as suggested in [16], the crack propagates along with martensite formation of the specimen. Martensite formation in an extended volume around and in front of the crack was verified experimentally by the in-situ X-ray diffraction experiments in references [16] and [19]. These in-situ experiments proved that after unloading the strain-induced martensite transforms back to austenite. This is shown in Figure 12a in [16] where no traces of the transformed martensite diffraction peaks were observed. In region III the load drops within an extremely short displacement path of the grips. According to crack-growth terminology [19], stable crack growth occurs in region II, whereas region III represents unstable crack-growth. The fracture test was conducted by displacement control at a displacement-speed of $8.33 \times 10^{-7} \mathrm{~m} / \mathrm{s}$ [16]. Figure $7 \mathrm{~b}$ is the enlarged part of the load-displacement plot, where the displacement scale, $\Delta$, is converted to time scale. It is plausible to assume that slow and fast crack propagation occurred in the stable and unstable crack-growth regimes, i.e. in region II and in region III, respectively. We assume further that the stable and unstable crack-growth regions correspond to the regimes where substantial whereas somewhat smaller amounts of remnant martensite were detected. Figures $6 \mathrm{a}$ and $7 \mathrm{a}$ indicate that the lengths of these two regions are about $500 \mu \mathrm{m}$ and $3 \mathrm{~mm}$, respectively. Beyond about $3 \mathrm{~mm}$ from the primary crack-tip, at the far end of the specimen, the CT-specimen loading is compressive which is not discussed here. The time periods corresponding to the stable, regime II, and unstable, regime III, crack-propagation, taken from Figure 7b, are about 120 and 25 seconds, respectively. These values provide crack- 
propagation rates of about $v_{\text {stab }} \cong 3.2( \pm 1) \times 10^{-6} \mathrm{~m} / \mathrm{s}$ and $v_{\text {unstable }} \cong 1.2( \pm 0.5) \times 10^{-4} \mathrm{~m} / \mathrm{s}$ in the stable and unstable crack-growth regimes, respectively. Crack-propagation in the unstable regime is more than one order of magnitude faster than in the stable one. The errors in crack propagation rates are taken from the uncertainties of the boundaries of regimes in Figure $7 \mathrm{~b}$.

The in-situ synchrotron and the post-mortem laboratory X-ray diffraction experiments revealed two different, however, complementary aspects of the forward and reverse transformation of stress induced martensite in pseudoelastic SMA. The synchrotron experiments $[16,19]$ revealed the static spatial extension of transformed martensite when the load was below the critical level for crack propagation. These experiments have shown that after unloading martensite transforms completely back to austenite. The present post-mortem depth profiling experiments revealed the presence of about $30 \%$ irreversible martensite extending into a depth of 15 to $20 \mu \mathrm{m}$ below and about $500 \mu \mathrm{m}$ along the path travelled by the crack tip in the stable crack-propagation regime. In the unstable crack-propagation regime only about $10 \%$ or less remnant martensite could be found, which, however, extends to a deeper depth of about $60 \mu \mathrm{m}$ from the fracture surface. As mentioned before, the spatial distribution of remnant martensite correlates with the dislocation density in the same, B19', phase, however, it is in anti-correlation with the dislocation density in the parent, B2, austenite phase.

We interpret our results by taking two factors into account: the amount of stress $\sigma$ at the primary crack-tip during crack propagation and the effect of strain-rate $(S R)$ on pseudoelasticity. NematNasser et al. [41,42] observed a dependence of the mechanical behavior on $S R$ in pseudoelastic NiTi . With increasing $S R$, the horizontal stress-strain plateau, associated with the formation of stress-induced martensite, see Figure 2a, become inclined. This effect is rationalized by the release of latent heat counteracting the transformation process. Furthermore, there is a critical strain-rate, $S R_{\text {critical }}$, where the transition stresses for stress-induced martensite, $\sigma_{\mathrm{SIM}}$, reaches the yield stress, $\sigma_{\mathrm{Y}-\mathrm{A}}$, of plastic deformation of the austenite parent phase. With increasing $S R, \sigma_{\mathrm{SIM}}$ increases beyond $\sigma_{\mathrm{Y}-\mathrm{A}}$. Using the method of split Hopkinson pressure bar the critical strain rate in NiTi-SMAs was estimated to be $S R_{\text {critical }} \cong 1000 \mathrm{~s}^{-1}$ [42]. Using similar techniques Guo et al. [43] found that at very high $S R$ s the stress-induced pseudoelatic martensite formation becomes completely suppressed. 
Freund et al. [44,45] estimated the $S R$ within the plastic zone in front of the primary crack-tip of a cleavage micro-crack in an iron single crystal as large as $10^{6}$ to $10^{7} \mathrm{~s}^{-1}$. They have shown that the $S R$ is proportional to the crack-propagation velocity, $v$, and inversely proportional to the elastic energy release-rate, $\mathrm{G}$ (see equation 1.2 in [45]). They noted that in macroscopic cleavage cracks $\mathrm{G}$ can be larger by two orders of magnitude, but even in such cases the $S R$ will be in the range between $10^{4}$ to $10^{5} \mathrm{~s}^{-1}$. We can assume that the crack-propagation velocity in our experiment is about an order of magnitude smaller than in a macroscopic cleavage crack. In our case this would mean that the $S R$ in the plastic zone at the primary crack-tip is of the order of $10^{3}$ to $10^{4} \mathrm{~s}^{-1}$. This value is close to the critical $S R$ reported by Guo et al. [43], i.e. $S R_{\text {critical }} \cong 1000 \mathrm{~s}^{-1}$.

The results of the present work are interpreted on the basis of a scenario where crack extension rates strongly increase, as the crack moves through regimes II to IV. This leads to different stress distributions in front of the propagating primary crack-tip. Figures $7 \mathrm{c}$ and $7 \mathrm{~d}$ show the two different stress field distributions in regimes II and III schematically, as the crack propagation proceeds. Figure $7 \mathrm{c}$ shows the situation for the entire crack-path range, as long as the crack proceeds in regime II. Here a short crack with stable and slow crack propagation is assumed. Close to the primary crack-tip there is a zone consisting of plastically deformed, detwinned martensite extending over about $500 \mu \mathrm{m}$. This true plastic zone is associated with the yield stress of stress-induced martensite, $\sigma_{\mathrm{Y}-\mathrm{SIM}}$. The lower stress plateau, $\sigma_{\mathrm{SIM}}$, where stress-induced martensite forms, is the pseudoelastic zone where stress-induced martensite is present which, however, is plastically undeformed. Towards the end of regime III, the austenite phase is elastically loaded. As soon as the crack tip moves on and leaves regime II, the loading stresses are drop down. In all regions along the crack path, at first the stresses increase, followed by stress relaxation. In the early stages of crack propagation this stress increase and subsequent decrease is slow.

The situation changes completely when the crack proceeds into regime III. Here crack propagation becomes unstable and fast. The far field stress distribution is still elastic and does not differ from the situation in Figure 7a. As stresses increase beyond $\sigma_{\mathrm{SIM}}$, indicated by the dashed horizontal line for the lower stress plateau in Figure 7a, martensite starts to transform. The large 
$S R$ conditions are producing adiabatic latent heat and the specimen heats up. The critical stress of stress-induced martensite is strongly temperature dependent, where the temperature dependence is of Clausius-Clapeyron type. As a consequence, stresses continuously increase closer to the crack tip in regime III, as indicated schematically in Figure 7d. In this figure we consider a hypothetical situation where close to the crack tip no more stress-induced martensite can form because the self-heating raised the temperature above $M_{d}$. (Here $M_{d}$ denotes the temperature above which no stress-induced martensite can form [3]). Due to the partial inhibition of stressinduced martensite-formation the stress plateau, close to the crack tip, raises to the yield stress of austenite, $\sigma_{\mathrm{Y}-\mathrm{A}}$, as shown in Figure $7 \mathrm{~d}$. The schematic results in Figure $7 \mathrm{~d}$ must be interpreted with care, because temperatures should not increase to values high enough to fully suppress the formation of stress-induced martensite. However, it is clear that adiabatic heating makes the formation of stress induced martensite more difficult and dislocation plasticity must be invoked to rationalize the plastic zone close to the crack tip. This qualitative picture explains two experimental findings. First, the austenitic regions suffer stronger plastic deformation and show higher dislocation densities, as shown in Figures 5b and 5c. Second, at higher crack propagation rates less martensite can be detected close to the rupture path, as shown in Figure 6a.

\section{Conclusions}

In the present work the fracture surface regions of a broken miniature pseudoelastic NiTi CT specimen were investigated, along which the crack tip propagated during the fracture mechanics experiment. X-ray line profile analysis was used to study the amount of martensite and the density of dislocations.. Along the fracture surface, three locations were monitored, one close to the tip of the original fatigue pre-crack, one in the center of the fracture surface and one at the far of the specimen. Careful step by step etching was used to remove thin layers of material parallel to the fracture surface in order to determine the depth profile of remnant martensite fractions and the dislocation densities in austenite and martensite. The results of the present study allow the following conclusions:

(1) X-ray line profile analysis can be used to identify the part of the stress affected zone in front of a crack tip which is due to dislocation plasticity (true plastic zone size). 
(2) Our results clearly show, that the remnant martensite phase in front of the crack tip of the pseudoelastic material, which does not transform back on unloading, is stabilized by large dislocation densities in the two phases.

(3) Our X-ray results were correlated with the dynamics of the load displacement data from the fracture mechanics experiment. In the stage where loads increase or remain constant ( this is the regime of static loading and stable crack growth), we observe smaller stress affected zones with higher dislocation densities and higher amounts of remnant martensite. In contrast, in regions where the load decreases but the speed of crack-propagation increases (unstable crack growth, fracture), pseudoelastic martensite formation becomes inhibited.

(4) The spatial extension of regions with remnant martensite are about one order or magnitude smaller than the volume affected by the formation of stress induced martensite during crackpropagation as observed by Gollerthan et al. [16,19].

(5) The true plastic zone at the actual primary crack-tip and the spatial extension of remnant martensite extend only into a few grains around the primary crack-tip and below the fracture surface.

\section{Acknowledgements}

T.U. is grateful to the Humboldt Foundation of Germany for supporting this research. JF, SG and GE acknowledge funding by the German Research Association (DFG) through project C1 of SPP 1544 (Ferroic Cooling). G.R. gratefully acknowledges the support of the János Bolyai Research Fellowship of the Hungarian Academy of Sciences. The authors thank Dr G. Csiszár for the assistance in carrying out the X-ray diffraction experiments. 
2

3

4

5

6

7

8

9

10

11

12

13

14

15

16

17

18

19

20

21

22

23

24

25

26

27

28

29

30

31

32

33

34

35

36

37

38

39

40

41

42

43

44

45

46

47

48

49

50

51

52

53

54

55

56

57

58

59

60 \\ Page 15 of 28}

Journal of Materials Research

1

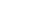

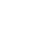

17

20

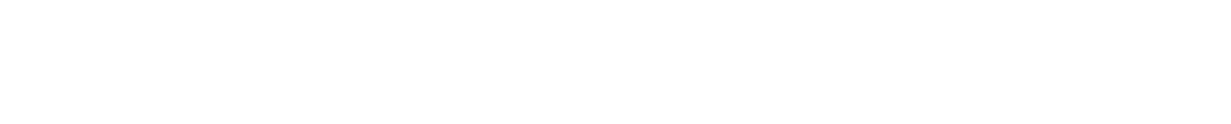

8




\section{References}

1. K. Otsuka and C.M. Waymann: Shape Memory Materials, Cambridge University Press, Cambridge, 1998.

2. H. Funakubo: Shape Memory Alloys, Gordon and Breach, New York, 1987.

3. J. Frenzel, E.P. George, A. Dlouhy, C. Somsen, M.F.X. Wagner and G. Eggeler: Influence of $\mathrm{Ni}$ on martensitic phase transformations in NiTi shape memory alloys. Acta Mater., 58, 3444 (2010).

4. J. Frenzel, A. Wieczorek, I. Opahle, B. Maaß, R. Drautz and G. Eggeler: On the effect of alloy composition on martensite start temperatures and latent heats in $\mathrm{Ni}$-Ti-based shape memory alloys. Acta Mater., 90, 213 (2015).

5. J. Van Humbeeck: Non-medical applications of shape memory alloys. Mat. Sci. Eng., A273-275, 134 (1999).

6. T. Duerig, A. Pelton and D. Stöckel: An overview of nitinol medical applications. Mat. Sci. Eng., A273-275, 149 (1999).

7. V.G. Pushin, V.V. Stolyarov, R.Z. Valiev, T.C. Lowe and Y.T. Zhu. Nanostructured TiNibased shape memory alloys processed by severe plastic deformation. Mat. Sci. Eng., A410, 386 (2005).

8. R. Valiev, D. Gunderov, E. Prokofiev, V. Pushin and Y. Zhu: Nanostructuring of TiNi alloy by SPD processing for advanced properties. Mater. Trans., 49, 97 (2008).

9. C. Grossmann, J. Frenzel, V. Sampath, T. Depka, A. Oppenkowski, C. Somsen, K. Neuking, W. Theisen and G. Eggeler: Processing and property assessment of NiTi and NiTiCu shape memory actuator springs. Mat.-Wiss. u. Werkstofftechn., 39, 499 (2008).

10. S.W. Robertson, A.R. Pelton and R.O. Ritchie: Mechanical fatigue and fracture of Nitinol., Int. Mater. Rev., 57, 1 (2012).

11. M. Rahim, J. Frenzel, M. Frotscher, J. Pfetzing-Micklich, R. Steegmüller, M. Wohlschlögel, H. Mughrabi and G. Eggeler: Impurity levels and fatigue lives of pseudoelastic NiTi shape memory alloys. Acta Mater., 61, 3667 (2013).

12. M. Launey, S.W. Robertson, W. Scott, L. Vien, K. Senthilnathan, Ch. Karthikeyan, P. Chintapalli and A.R. Pelton: Influence of microstructural purity on the bending fatigue 
behavior of VAR-melted superelastic Nitinol. J. Mech. Behavior Biomed. Mater., 34, 181 (2014).

13. S. Fähler, U.K. Rößler, O. Kastner, J. Eckert, G. Eggeler, H. Emmerich, P. Entel, S. Müller, E. Quandt and K. Albe: Caloric Effects in Ferroic Materials: New Concepts for Cooling. Adv. Eng. Mater., 14, 10 (2012).

14. T. Baxevanis and D.C. Lagoudas: Fracture mechanics of shape memory alloys: review and perspectives. Int. J. Fracture. 191, 191 (2015).

15. S. Gollerthan, D. Herberg, A. Baruj and G. Eggeler: Compact tension testing of martensitic/pseudoplastic NiTi shape memory alloys. Mat. Sci. Eng., A481 156 (2008).

16. S. Gollerthan, M.L. Young, A. Baruj, J. Frenzel, W.W. Schmahl and G. Eggeler: Fracture mechanics and microstructure in NiTi shape memory alloys. Acta Mater., 57, 2015 (2009).

17. S. Gollerthan, M.L. Young, K. Neuking, U. Ramamurty and G. Eggeler: Direct physical evidence for the back-transformation of stress-induced martensite in the vicinity of cracks in pseudoelastic NiTi shape memory alloys. Acta Mater., 57, 5892 (2009).

18. C. Maletta, L. Bruno, P. Corigliano, V. Crupi and E. Guglielmino: Crack-tip thermal and mechanical hysteresis in Shape Memory Alloys under fatigue loading. Mat. Sci. Eng., A616, 281 (2014).

19. M.L. Young, S. Gollerthan, A. Baruj, J. Frenzel, W.W. Schmahl and G. Eggeler: Strain mapping of crack extension in pseudoelastic NiTi shape memory alloys during static loading. Acta Mater., 61, 5800 (2013).

20. E. Sgambitterra, C. Maletta and F. Furgiuele: Investigation on Crack Tip Transformation in NiTi Alloys: Effect of the Temperature. Shape Mem. Superelast., 1. 275 (2015).

21. T. Baxevanis, Y. Chemisky and D.C. Lagoudas: Finite element analysis of the plane strain crack-tip mechanical fields in pseudoelastic shape memory alloys. Smart Mater. Struct., 21, 094012 (2012).

22. T. Baxevanis, A.F. Parrinello and D.C. Lagoudas: On the fracture toughness enhancement due to stress-induced phase transformation in shape memory alloys. Int. J. Plasticity, 50, 158 (2013).

23. T. Baxevanis, C.M. Landis and D.C. Lagoudas, On the Fracture Toughness of Pseudoelastic Shape Memory Alloys. J. Appl. Mech., 81, 041005 (2014). 
24. T. Baxevanis, C.M. Landis and D.C. Lagoudas: On the Effect of Latent Heat on the Fracture Toughness of Pseudoelastic Shape Memory Alloys. J. Appl. Mech., 81, 101006 (2014).

25. G. Stam and E. Giessen: Effect of reversible phase transformations on crack growth. Mech. Mater., 21, 51 (1995).

26. Y. Freed and L. Banks-Sills: Crack growth resistance of shape memory alloys by means of a cohesive zone model. J. Mech. Phys. Solids, 55, 2157 (2007).

27. T. Ungár, S. Ott, P. G. Sanders, A. Borbély and J. R. Weertman: Dislocations, grain size and planar faults in nanostructured copper determined by high resolution X-ray diffraction and a new procedure of peak profile analysis. Acta Mater., 46, 3693 (1998).

28. T. Ungár, I. Dragomir, Á. Révész and A. Borbély: The contrast factors of dislocations in cubic crystals: the dislocation model of strain anisotropy in practice. J. Appl. Cryst., 34, 298 (1999).

29. G. Ribárik and T. Ungár: Characterization of the microstructure in random and textured polycrystals and single crystals by diffraction line profile analysis. Mater. Sci. Eng., A528, 112 (2010).

30. T. Ungár, L. Balogh and G. Ribárik: Defect-Related Physical-Profile-Based X-Ray and Neutron Line Profile Analysis. Metall. Mater. Trans., A41, 1202 (2010).

31. G. Ribárik, B. Jóni and T. Ungár: Monte-Carlo and least-squares procedures combined for global minimum of the physical parameters in line profile analysis. in preparation.

32. M. A. Krivoglaz: X-Ray and Neutron Diffraction in Nonideal Crystals, Springer, Berlin, Heidelberg, 1996.

33. Wilkens M: Theoretical aspects of kinematical X-ray diffraction profiles from crystals containing dislocation distributions. in Fundamental Aspects of Dislocation Theory, Eds. J.A. Simmons, R. de Wit, R. Bullough, vol. II., Nat. Bur. Stand. (US) Spec. Publ. No. 317, Washington, DC, USA, 1970, p. 1195.

34. I. Groma, T. Ungár and M. Wilkens: Asymmetric X-ray Line Broadening of Plastically Deformed Crystals. I. Theory. J. Appl. Cryst., 21, 47 (1988).

35. J. E. Bailey and P. B. Hirsch: The dislocation distribution, flow stress, and stored energy in cold-worked polycrystalline silver. Phil. Mag., 5, 485 (1960). 
36. T. Ungár and G. Tichy: The effect of dislocation contrast on X-ray line profiles in untextured polycrystals. Phys. Stat. Sol., A147, 425 (1999).

37. G. Csiszár, K. Pantleon, H. Alimadadi, G. Ribárik and T. Ungár: Dislocation density and Burgers vector population in fiber-textured Ni thin films determined by high-resolution Xray line profile analysis. J. Appl. Cryst., 45, 61 (2012).

38. B. Jóni, T. Al-Samman, S. G. Chowdhury, G. Csiszár and T. Ungár: Dislocation densities and prevailing slip-system types determined by X-ray line profile analysis in a textured AZ31 magnesium alloy deformed at different temperatures. J.Appl.Cryst., 46, 55 (2013).

39. T. Ungár, G. Tichy, J. Gubicza and R. J. Hellmig: Correlation between subgrains and coherently scattering domains. Powder Diffraction, 20, 366 (2005).

40. Gy. Zilahi, T. Ungár and G. Tichy: A common theory of line broadening and rocking curves. J. Appl. Cryst., 48, 418 (2015).

41. S. Nemat-Nasser, J.-Y. Choi, W.-G. Guo and J. B. Isaacs: Very high strain-rate response of a NiTi shape-memory alloy. Mech Mater., 37, 287 (2005).

42. S. Nemat-Nasser and W.-G. Guo: Superelastic and cyclic response of NiTi SMA at various strain rates and temperatures. Mechanics Mater., 38, 463 (2006).

43. W. G. Guo, J. Su, Y. Su and S.Y. Chu: On phase transition velocities of NiTi shape memory alloys. J. Alloys Comp., 501, 70 (2010).

44. L. B. Freund and J. W. Hutchinson: High strain-rate crack growth in rate-dependent plastic solids. J. Mech. Phys. Solids, 33, 169 (1985).

45. L. B. Freund, J. W. Hutchinson and P. S. Lam: Analysis of high-strain-rate elastic-plastic crack growth. Eng. Fract. Mech., 23, 119 (1986).

46. G. T. Grey-III: High-Strain-Rate Deformation: Mechanical Behavior and Deformation Substructures Induced. Annu. Rev. Mater. Res., 42, 285 (2012). 


\section{Captions}

Figure 1.

Fracture mechanics applied in the present work. a) Geometry of our CT specimen, schematic illustration showing b) mechanical loading prior to crack growth c) unstable crack growth when $\mathrm{K}_{\mathrm{I}}{ }^{*}$ is reached, $\mathrm{d}$ ) fracture. The dashed regions represent the volume close to the fracture surface, which is investigated in the present work through XRD profile analysis.

Figure 2.

(a) Typical stress strain curve with the long pseudoplastic plateau at room temperature during loading in a uniaxial tensile test. (b) The applied load, $\mathrm{P}$ as a function of displacement, $\Delta$ of the grips in the CT specimen investigated in the present work.

\section{Figure 3.}

(a) The spatial distribution of the volume fraction of transformed martensite, B2/B19', around the crack tip, in an identical CT specimen as the one investigated here, determined by high energy Xray diffraction in [16]. The specimen in [16] was strained up to the load of about $70 \%$ before the initiation of crack growth. (b) The enlarged part of (a) around the crack tip with indicating the positions where the present X-ray diffraction experiments were carried out on the fractured specimen. (By courtesy from the authors of [16].)

Figure 4.

(a) The measured (open circles) and fitted (red line) diffraction pattern measured on the fracture surface at the primary crack-tip. The difference between the measured and fitted data is shown in the bottom of the figure. Here the fitting was carried out by the CMWP procedure. (b) A more detailed subdivision of the overlapping austenite and martensite peaks, where the sub-peaks corresponding to the five strongest B19' martensite reflections shown as black solid lines and the 110 austenite peak as dashed blue line. (c) Measured (open circles) and fitted (red lines) diffraction patterns corresponding to the fracture surface at a distance of $4 \mathrm{~mm}$ from the primary 
crack-tip. (d) Measured (open circles) and fitted (red lines) diffraction patterns $59.6 \mu \mathrm{m}$ below the fracture surface, below the primary crack-tip.

\section{Figure 5.}

(a) Dislocation density in the B19' remnant martensite phase as a function of depth and distance from the primary crack-tip. (b) Dislocation density in in the B2 austenite phase as a function of depth and distance from the primary crack-tip. (c) Dislocation density, in logarithmic scale, in the B2 austenite phase as a function of depth and distance from the primary crack-tip. The experimental error is $\pm 2 \times 10^{14} \mathrm{~m}^{-2}$ in the smaller and $\pm 5 \times 10^{15} \mathrm{~m}^{-2}$ in the larger dislocation density ranges, respectively.

Figure 6.

(a) The fraction of irreversible-martensite transformed during fracture as a function of depth and distance from the primary crack-tip. The experimental error is \pm 0.02 in the smaller and \pm 0.04 in the larger fraction values, respectively. (b) The area average mean crystallite size in the B19' remnant martensite phase as a function of depth and distance from the primary crack-tip. (c) The area average mean crystallite size in the B2 austenite phase as a function of depth and distance from the primary crack-tip. The experimental error is $\pm 2 \mathrm{~nm}$ in the smaller and $\pm 5 \mathrm{~nm}$ in the larger $\langle\mathrm{x}>$ area values, respectively.

Figure 7.

(a) Schematic drawing of the transformed (color scale used in Fig. 7a in [12] and in Fig. 3a here) and the irreversible martensite (black and light brown) along the fracture surface. (b) Enlarged part of the load-displacement plot in Fig. 2b, with the displacement scale replaced by the time scale. (c) Schematic illustration of stress distributions in front pf the primary crack-tip for static loading or slow crack propagation, (d) for fast and unstable crack growth and for longer cracks. Note that $\sigma_{\mathrm{Y}-\mathrm{A}}$ in $(\mathrm{d})$ is larger than $\sigma_{\mathrm{Y}-\mathrm{SIM}}$ in (c), $\sigma_{\mathrm{Y}-\mathrm{A}}>\sigma_{\mathrm{Y}-\mathrm{SIM}}$. 


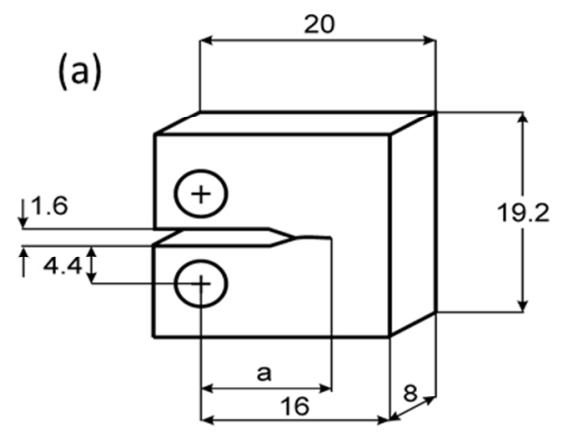

(b)

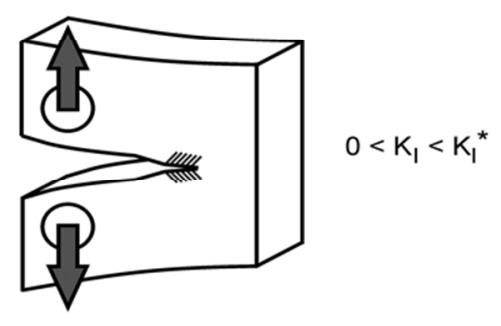

(c)

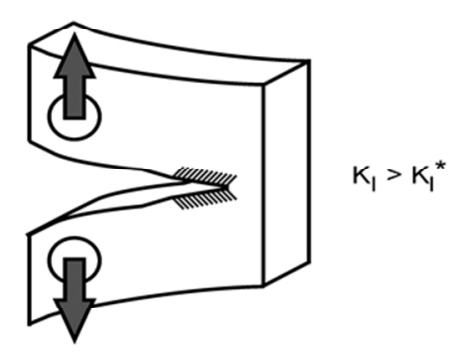

(d)
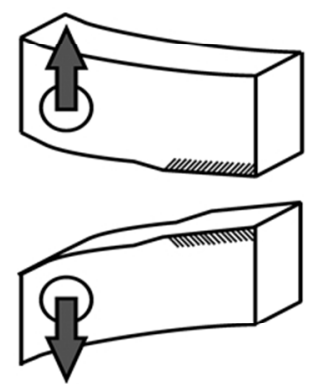

$254 \times 190 \mathrm{~mm}(96 \times 96$ DPI) 


1
2
3
4
5
6
7
8
9
10
11
12
13
14
15
16
17
18
19
20
21
22
23
24
25
26
27
28
29
30
31
32
33
34
35
36
37
38
39
40
41
42
43
44
45
46
47
48
49
50
51
52
53
54
55
56
57
50

(a)
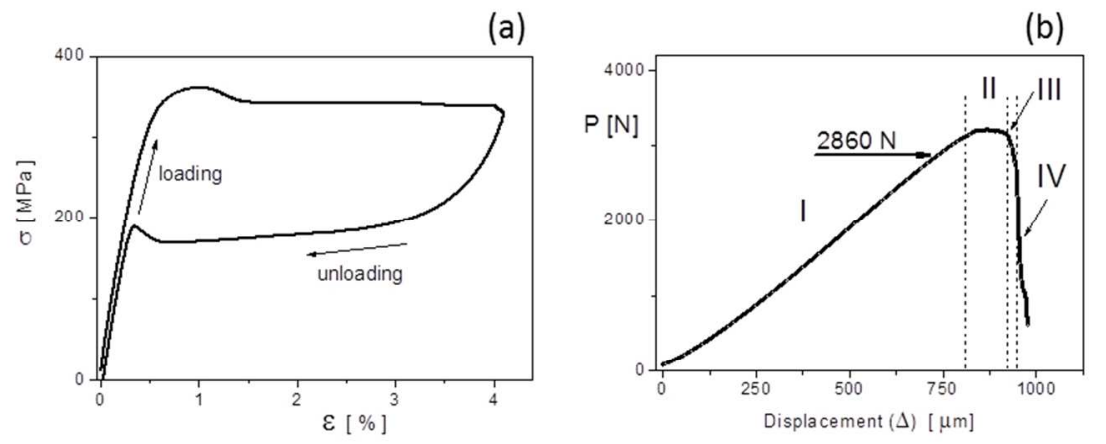

$254 \times 190 \mathrm{~mm}(96 \times 96 \mathrm{DPI})$ 
(a)

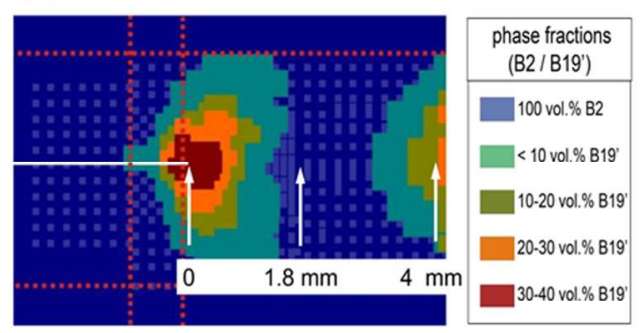

(b)

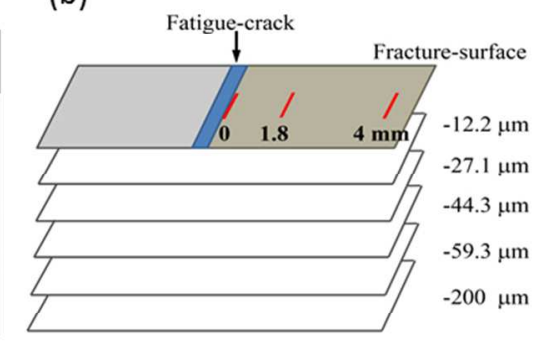

$254 \times 190 \mathrm{~mm}(96 \times 96 \mathrm{DPI})$ 


1
2
3
4
5
6
7
8
9
10
11
12
13
14
15
16
17
18
19
20
21
22
23
24
25
26
27
28
29
30
31
32
33
34
35
36
37
38
39
40
41
42
43
40
45
49
50
51
52
53
55
50
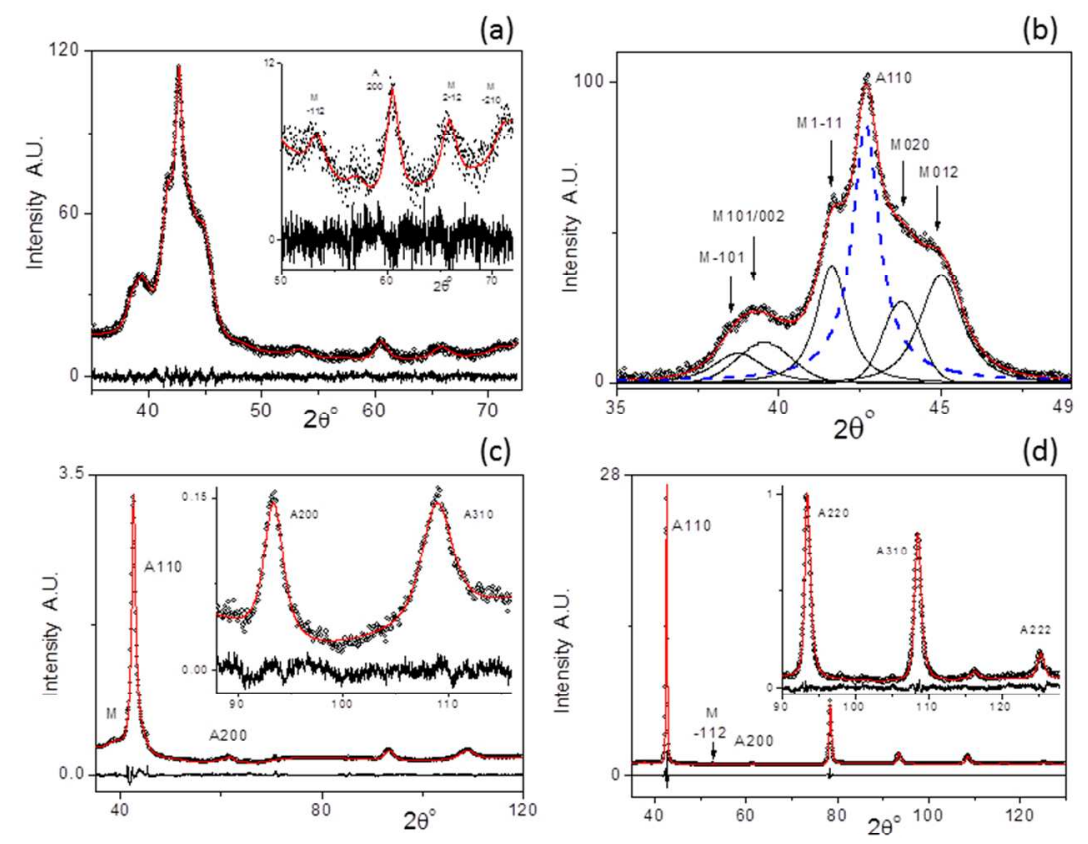

$254 \times 190 \mathrm{~mm}(96 \times 96$ DPI $)$ 


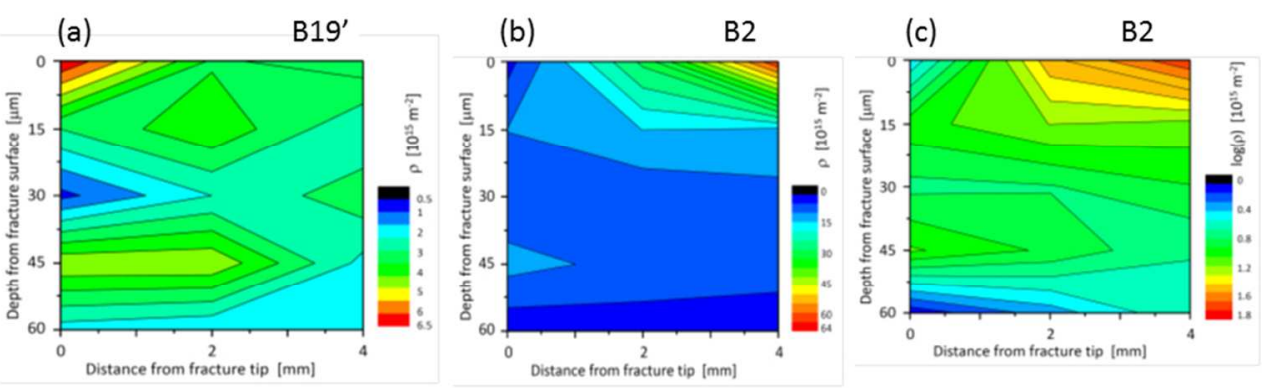

254x190mm (96 x 96 DPI) 


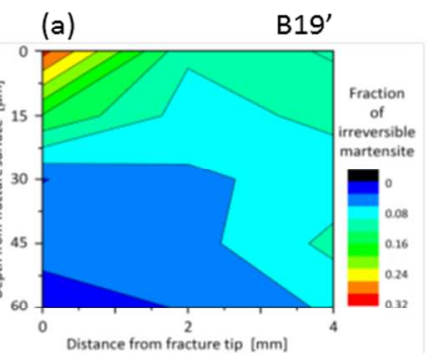

(b)

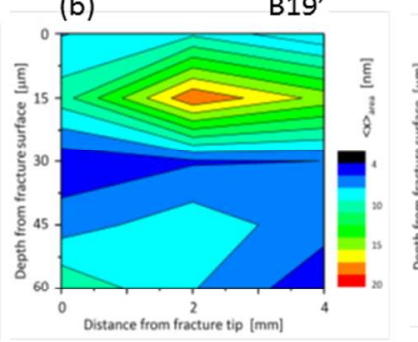

(c)

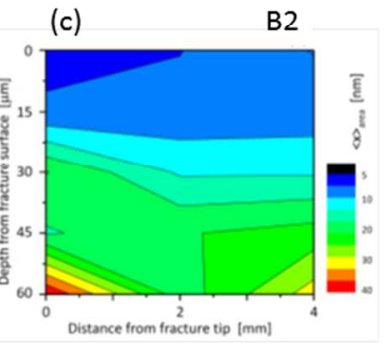

254×190mm (96 × 96 DPI) 
(a)

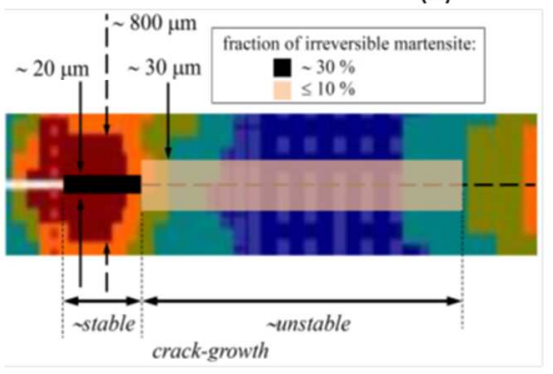

(c)
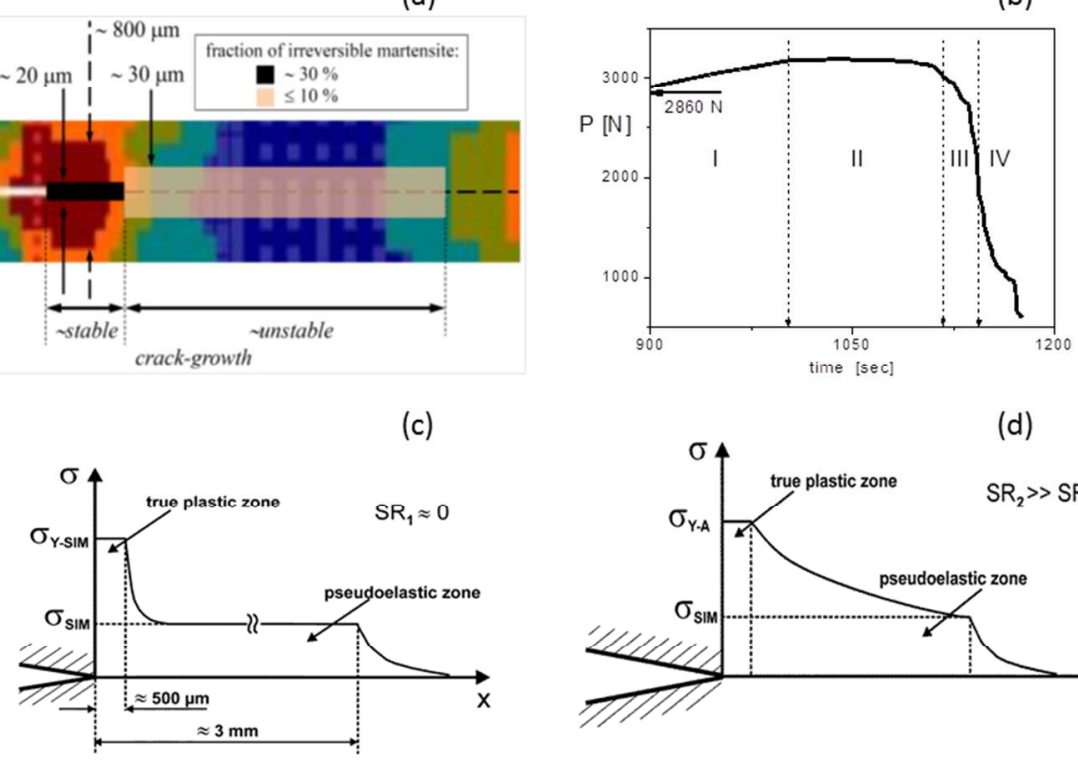

(b) 